\title{
Production of cecropin A antimicrobial peptide in rice seed endosperm
}

\author{
Mireia Bundó ${ }^{1}$, Laura Montesinos², Esther Izquierdo ${ }^{3}$, Sonia Campo ${ }^{1}$, Delphine Mieulet ${ }^{4}$, Emmanuel Guiderdoni $^{4}$, \\ Michel Rossignol ${ }^{3}$, Esther Badosa², Emilio Montesinos², Blanca San Segundo ${ }^{1}$ and María Coca ${ }^{1 *}$
}

\begin{abstract}
Background: Cecropin A is a natural antimicrobial peptide that exhibits rapid, potent and long-lasting lytic activity against a broad spectrum of pathogens, thus having great biotechnological potential. Here, we report a system for producing bioactive cecropin A in rice seeds.

Results: Transgenic rice plants expressing a codon-optimized synthetic cecropin A gene drived by an endosperm-specific promoter, either the glutelin B1 or glutelin B4 promoter, were generated. The signal peptide sequence from either the glutelin B1 or the glutelin B4 were N-terminally fused to the coding sequence of the cecropin A. We also studied whether the presence of the KDEL endoplasmic reticulum retention signal at the C-terminal has an effect on cecropin A subcellular localization and accumulation. The transgenic rice plants showed stable transgene integration and inheritance. We show that cecropin A accumulates in protein storage bodies in the rice endosperm, particularly in type II protein bodies, supporting that the glutelin $\mathrm{N}$-terminal signal peptides play a crucial role in directing the cecropin $A$ to this organelle, independently of being tagged with the KDEL endoplasmic reticulum retention signal. The production of cecropin A in transgenic rice seeds did not affect seed viability or seedling growth. Furthermore, transgenic cecropin A seeds exhibited resistance to infection by fungal and bacterial pathogens (Fusarium verticillioides and Dickeya dadantii, respectively) indicating that the in planta-produced cecropin A is biologically active.
\end{abstract}

Conclusions: Rice seeds can sustain bioactive cecropin A production and accumulation in protein bodies. The system might benefit the production of this antimicrobial agent for subsequent applications in crop protection and food preservation.

Keywords: Rice, Antimicrobial peptides, Cecropin A, Endosperm, Protein bodies, Pathogen resistance, Fusarium verticillioides, Dickeya dadantii, Oryza sativa

\section{Background}

Antimicrobial peptides (AMPs) are evolutionarily conserved components of the innate immune system of most living organisms. AMPs show a high degree of sequence diversity but share some characteristics including their predominantly cationic character, a high content of hydrophobic residues, and an amphipathic structure. They are also natural antibiotics that exhibit rapid, potent and longlasting activity against a broad spectrum of pathogens by affecting conserved features of microbial cell membranes [1]. AMPs are emerging as valuable agents for crop protection [2-4], food preservation [5,6], and pharmaceuticals

\footnotetext{
* Correspondence: maria.coca@cragenomica.es

${ }^{1}$ Centre for Research in Agricultural Genomics (CRAG), CSIC-IRTA-UAB-UB.

Edifici CRAG, Campus de la UAB, 08193 Bellaterra, Barcelona, Spain

Full list of author information is available at the end of the article
}

for both human and animal health [7-9] to alleviate the growing problem of conventional antibiotic resistance and the shortage of effective compounds. However, the high cost of chemical synthesis or the low yield obtained via purification from natural sources has limited the use of AMPs in these fields, particularly in applications with little added value.

Plants are promising biofactory systems for AMPs; they are economical to grow, easily scalable and generally regarded as safe because of the low risk of contamination with human and animal pathogens [10]. Plants have successfully been used for the production of different proteins for therapeutic and technological applications [11]. However, little attention has been paid to the use of plants as biofactories for AMPs. Evidence indicating that plants can sustain AMP production can be found in the literature, 
since plants have been used for the heterologous production of AMPs with the aim of improving host resistance to pathogen infection [3]. No extensive efforts were made in those studies, however, to quantify the amount of AMP produced in the transgenic plants.

Seeds naturally accumulate proteins, packed in a dehydrated optimal biochemical environment for long-term storage. Thus, this organ seems suitable for the production of stable large amounts of AMPs in a compact biomass. In particular, rice seeds are considered as a good biofactory due to high grain yields. Furthermore, rice is easy to transform, can be grown under containment conditions, and the risk of unintended gene flow is minimal compared with other crops [12].

The rice endosperm is an appropriate tissue for the heterologous production of proteins of interest [13-17]. This organ occupies most of the space within the rice seed. Endosperm cells mostly contain starch granules and proteins, and are the major storage protein sink. In rice, $60 \%$ to $80 \%$ of all storage proteins are glutelins, which are insoluble in neutral saline solutions but soluble in acid or alkaline solutions [18]. They are classified into four groups (GluA, GluB, GluC and GluD) based on their amino acid sequence [19]. Some $20 \%$ to $30 \%$ of all rice seed proteins are alcohol-soluble prolamines [18]. Rice seeds also accumulate a salt-soluble globulin which comprises up to $5 \%$ of the seed protein [20]. These storage proteins are densely packed into specialized storage organelles called protein bodies (PBs). There are two types of PBs in rice seeds: PB-I and PB-II. The former are spherical protein inclusions that bud from the endoplasmic reticulum (ER) and in which prolamines are typically accumulated $[21,22]$. The later, also known as protein storage vacuoles (PSVs), contain glutelin and globulin proteins, and are characterized by their irregular shape, with a diameter of about $2-4 \mu \mathrm{m}$, and their highly uniform dense structure. Glutelins aggregate in PB-II and form protein inclusions with crystalline structures [21,23]. PB-II are derived from Golgi or may bypass the Golgi complex [24]. All storage proteins contain an $\mathrm{N}$-terminal signal peptide that mediates translocation into the ER, where the signal peptide is cleaved and the protein is transported to the appropriate storage compartment [25]. The seed storage organelles can contain recombinant proteins, offering stability in planta and allowing considerable accumulation [26].

The aim of this study is to explore the feasibility of using rice seed endosperm for the production of AMPs. Cecropin A was chosen as the AMP to be produced, based on its biotechnological potential. Cecropin A is a linear and cationic peptide isolated from insect haemolymph that shows potent lytic activity against important bacterial and fungal phytopathogens [27-29]. Its constitutive accumulation in transgenic rice plants has been shown to confer enhanced pathogen resistance [30]. Previous studies by our group demonstrated that transgenic rice plants constitutively expressing a cecropin $A$ gene designed to secret the encoded peptide in the extracellular space had an abnormal phenotype and were not fertile [30]. No effect on plant performance was observed in the transgenic rice plants that accumulated cecropin A in the ER, the plants accumulated low levels of the peptide in their leaves [30]. Here, we report the production and accumulation of bioactive cecropin A in rice endosperm without any impact on seed viability or seedling growth. Two different endospermspecific promoters were used to drive the expression of a codon-optimized synthetic cecropin $A$ gene $(\mathrm{Cec} A)$, namely the GluB1 and GluB4 promoters. The N-terminal signal peptide sequence of either the GluB1 or GluB4 protein was fused to the cecropin A sequence. Furthermore, two different $C e c A$ genes, encoding the cecropin $\mathrm{A}$ or cecropin A-KDEL peptide, were assayed to determine the effect of the ER retention signal (KDEL) on peptide accumulation and subcellular localization.

\section{Results}

\section{Generation of transgenic rice plants for cecropin A production}

Four different constructs were prepared for the expression of synthetic codon-optimized $\mathrm{Cec} A$ genes in rice seeds; they are shown in Figure 1A. They contain the promoter of either the GluB1 or the GluB4 gene, which encode the major rice seed storage proteins, to drive seed-specific expression of the synthetic genes. An endosperm-specific expression pattern has been reported for these two promoters [31]. Each construct incorporates a different chimeric $C e c A$ gene designed to study different targeting mechanisms of the encoded peptide. The chimeric genes consist of the $\mathrm{N}$-terminal signal peptide sequence of the corresponding glutelin $\mathrm{B} 1$ or $\mathrm{B} 4$ protein fused to the coding sequence of the cecropin A peptide; two of them also include the sequence encoding the $\mathrm{C}$-terminal $\mathrm{ER}$ retention signal (KDEL).

Transgenic rice plants were produced by Agrobacterium-mediated transformation using the hygromycin resistance gene as the selectable marker. After each transformation, hygromycin-resistant plants were obtained and transgene integration was verified by PCR analysis of (Additional file 1). No apparent adverse effects on the plant phenotype were observed under greenhouse conditions. Six independent lines per transformation event were selected to obtain the T2 homozygous progeny plants. The stability of the transgene integration and inheritance was monitored across generations by the hygromycin resistance phenotype encoded in the T-DNA.

\section{Accumulation of cecropin $A$ in rice seeds}

To determine whether the transgenic lines accumulated the transgene product, the presence of cecropin A in 

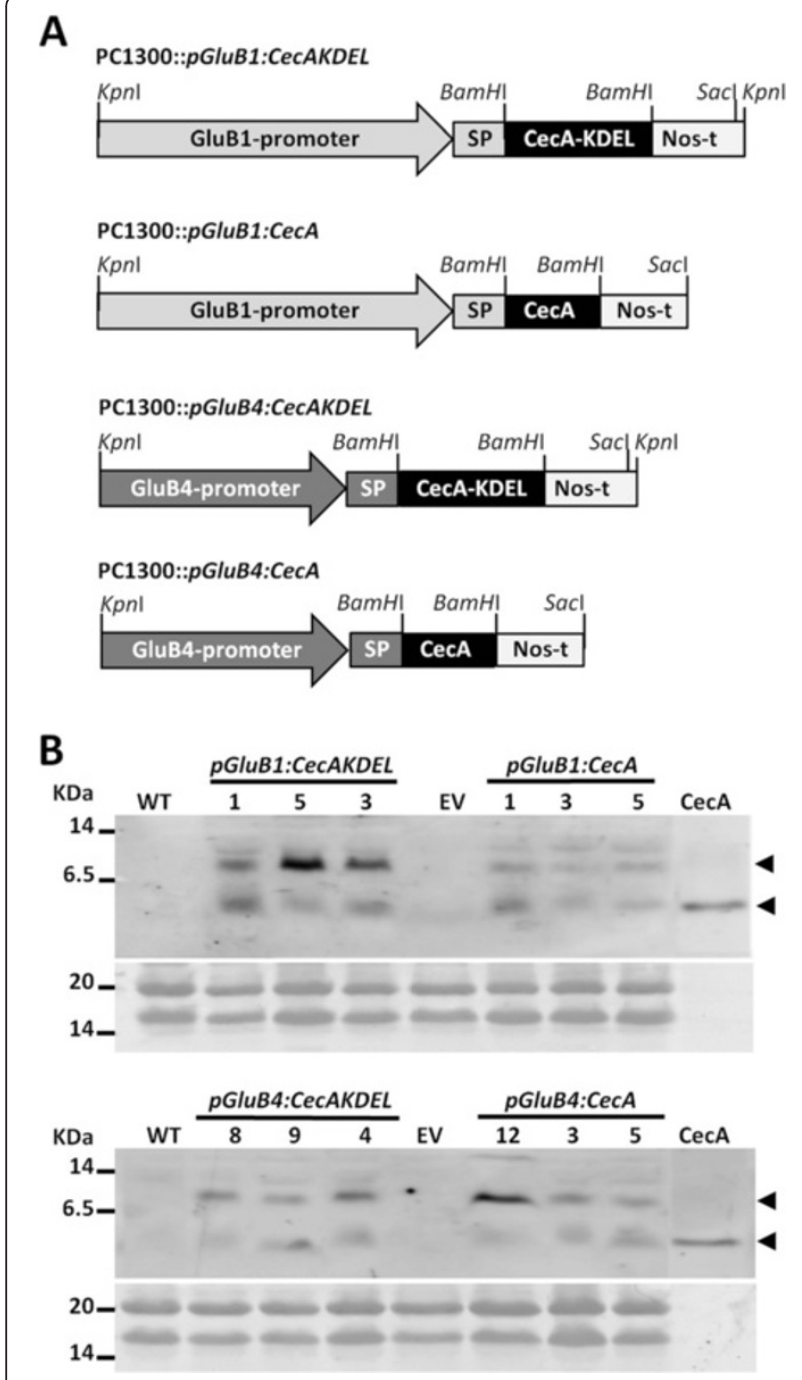

Figure 1 Generation of transgenic rice plants producing cecropin A. A. Schematic representation of the constructs. Expression of the synthetic CecA genes was controlled by the $2.3 \mathrm{~kb}$ GluB1 or the $1.4 \mathrm{~kb}$ GluB4 promoters and the nos terminator. Relevant restriction enzyme sites for cloning purposes are indicated. B. Cecropin A accumulation in transgenic rice plants. Immunoblot analysis using anti-cecropin $A$ antibodies of protein extracts from wild-type (WT) or transgenic seeds carrying the empty vector (EV) or the transgenes indicated. For comparative purposes, $50 \mathrm{ng}$ of synthetic cecropin A was run simultaneously in the tricine-SDS gels. Lower panels show Ponceau staining of protein samples.

seed protein extracts was analysed by immunoblot assays using specific antibodies. As shown in Figure 1B, the anticecropin A antibodies reacted with two major bands in the protein extracts obtained from transgenic seeds, which were absent in the extracts obtained either from wild-type or from the empty vector transformed seeds. The strongest signal corresponded to a peptide with a mobility around $8 \mathrm{kDa}$, which is compatible with a cecropin $\mathrm{A}$ dimer conformation (the theoretical molecular weight of cecropin A is $4 \mathrm{kDa}$ ), as reported previously for lines constitutively producing cecropin A [30] and as also shown in Figure 2A. A band with an estimated mobility approximately $4 \mathrm{kDa}$ that migrates similarly to the synthetic cecropin A was also detected in the cecropin A lines, which could correspond to the cecropin A monomeric peptide. The cecropin A dimer was consistently

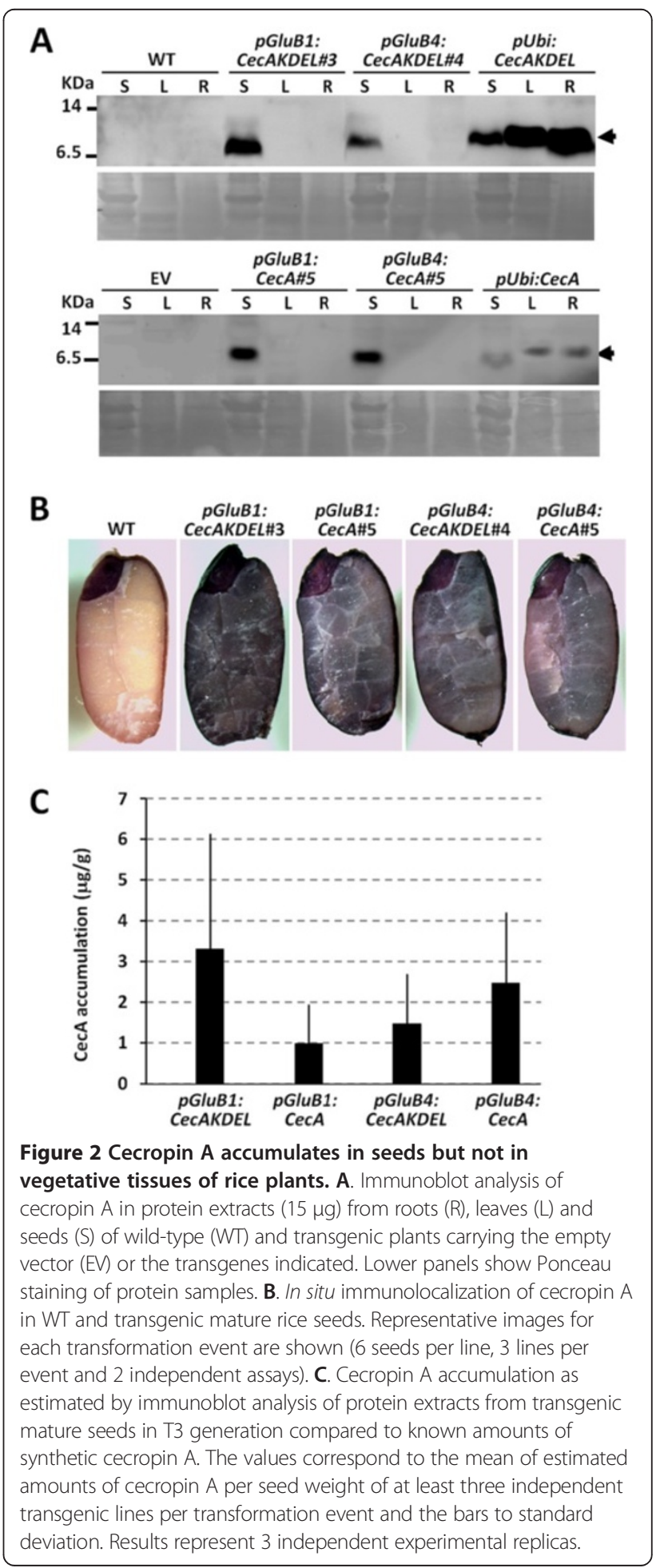


detected in all the transgenic lines and in all the immunoblot analyses conducted during the course of this work; whereas the monomeric cecropin A was not always detected, suggesting that the dimeric conformation was more stable. Figure $1 \mathrm{~B}$ also shows that cecropin A peptides were detected in all the lines carrying any of the four chimeric genes, indicating that the $\operatorname{Cec} A$ transgenes were properly expressed and their corresponding products accumulated in the rice seeds.

We then examined whether the glutelin promoters specifically direct $\operatorname{Cec} A$ gene expression specifically to seed and not to vegetative tissue, such as roots or leaves. To this end, protein extracts were prepared from the roots and leaves of representative lines per each transgene and subjected to Western blot analysis. As positive controls, protein extracts from transgenic lines expressing $\mathrm{Cec} A$ genes controlled by the maize ubiquitin-1 promoter were also included in this analysis. As shown in Figure 2A, cecropin A was detected in the protein extracts of seeds carrying any of the $C e c A$ genes controlled by glutelin promoters, whereas they were absent in the extracts from leaves and roots of the same plants. As expected, positive reactions were detected in the leaf and root protein extracts of the lines constitutively expressing $\mathrm{Cec} A$ genes. Thus, this analysis confirmed that cecropin A accumulated in rice seeds, but not in the vegetative tissues, when expression was controlled by either the GluB1 or the GluB4 promoter.

To further characterize the cecropin A lines, the distribution of the heterologous peptide in the seeds was analysed by in situ immunodetection. As shown in Figure 2B, a positive reaction was detected in the mature seeds of transgenic plants harbouring any of the four transgenes. Specific immunological reactions were detected in the endosperm of cecropin A seeds as compared to wild-type seeds. An unspecific reaction in embryo tissue was also observed in all the seeds analysed, including wild-type and empty vector seeds (Figure $2 \mathrm{~B}$ ). Therefore, the transgenic lines produced and accumulated cecropin $\mathrm{A}$ in the rice seed endosperm.

A comparative analysis of cecropin A accumulation in the different transgenic lines generated in this work was carried out. By comparing band intensities with those of known amounts of synthetic cecropin A, the cecropin A content in the lines was determined (Figure 2C). This study revealed variability in cecropin A accumulation between transgenic lines harbouring the same transgene, as well as in lines harbouring different transgenes. The accumulation levels ranged from 0.5 to $6 \mu \mathrm{g} / \mathrm{g}$ seed tissue. Similar accumulation levels were observed using either the GluB1 or GluB4 promoter, suggesting that the observed variability is associated with transgenesis rather with the activity of one or another promoter. Furthermore, the cecropin A levels were similar in seeds harbouring the transgenes with or without the KDEL extension sequence, indicating that the KDEL signal did not enhance accumulation of the peptide. Only one line carrying the $p G l u B 1: C e c A K D E L$ transgene (line 5) appeared to accumulate higher levels than the other transgenic lines. In addition, the observed variability in accumulation did not correlate with the transgene copy number of each line, as most of the lines generated contained one or two transgene insertions as estimated by quantitative PCR (Additional file 2).

\section{Cecropin A accumulates in PB-II}

Cecropin peptides are known to be highly susceptible to plant proteases, which limits their accumulation in plant tissues [27,32,33]. A priori, directing the cecropin A to endosperm PBs would protect it from host proteases. In order to determine whether cecropin A were accumulated in PBs of rice seeds, subcellular fractionation by centrifugation on a sucrose gradient was performed and the fractions were subjected to immunoblot analysis. Coomassie blue staining of equivalent protein fractions showed a clear enrichment of glutelin and prolamine proteins in the densest fraction (fraction 3, Figure 3A-B). Immunoblot analysis of gradient fraction proteins revealed the presence of cecropin A in fraction 3 in all the lines, whether they contained the KDEL extension or not (Figure 3C). These results demonstrate that cecropin A accumulates in dense seed protein organelles.

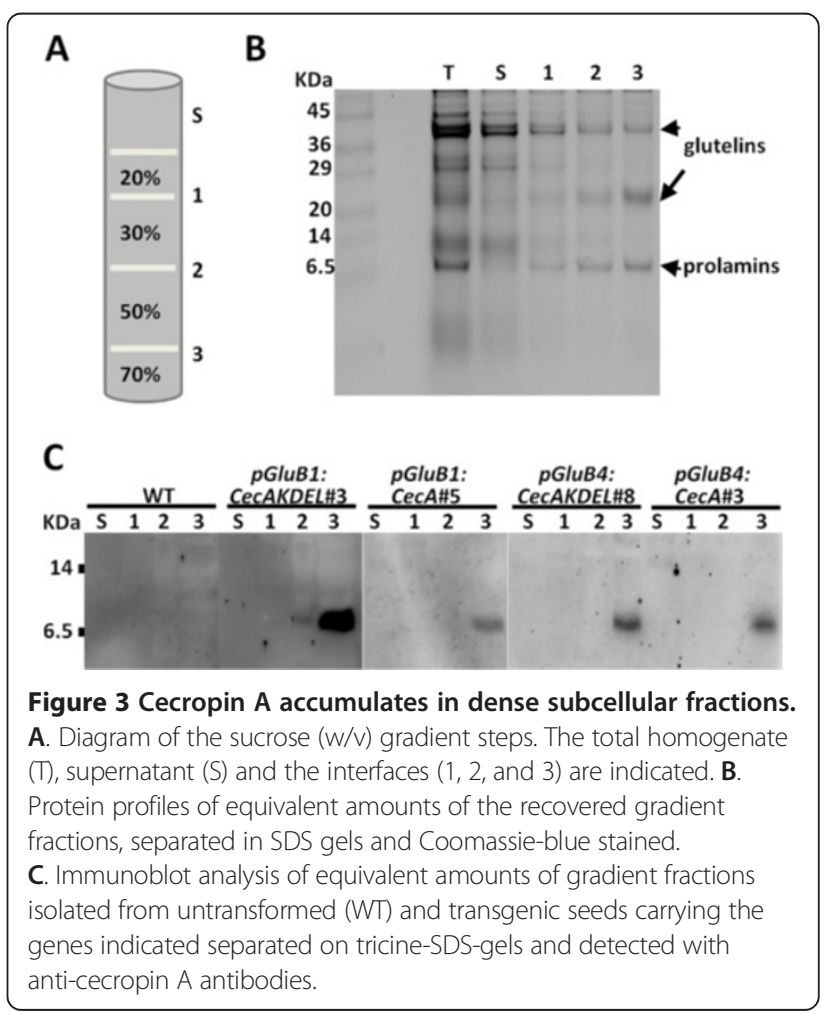


Furthermore, the subcellular localization of cecropin A was analysed by immunofluorescence microscopy in rice seed sections. As shown in Figure 4A, cecropin A (labelled in green) accumulated in small cytoplasmic vesicles of peripheral endosperm cells but it did not in wild-type seeds. These vesicles showed a similar appearance and abundance in all the cecropin A lines, as well as in the cecropin A-KDEL lines. As shown, they are smaller and less spherical than the rhodamine B-stained vesicles (Figure $4 \mathrm{~B}$, labelled in red), corresponding to prolaminecontaining PBs (PB-I). Rhodamine $\mathrm{B}$ hexyl ester binds strongly to rice prolamine and it is regularly used for fluorescent labelling of PB-I [34]. The merged images in Figure $4 \mathrm{~B}$ clearly show that cecropin A was absent from PB-I, since no colocalization is observed. When the glutelin-containing PBs (PB-II) were immunolabelled, fluorescence was detected in bodies that have a similar shape and size to bodies containing cecropin A (Figure 4C, labelled in blue). The merged images show frequent colocalization of glutelin and cecropin A signals; while some bodies were stained only in green or blue. These results indicate that cecropin $\mathrm{A}$, as well as the KDEL-tagged
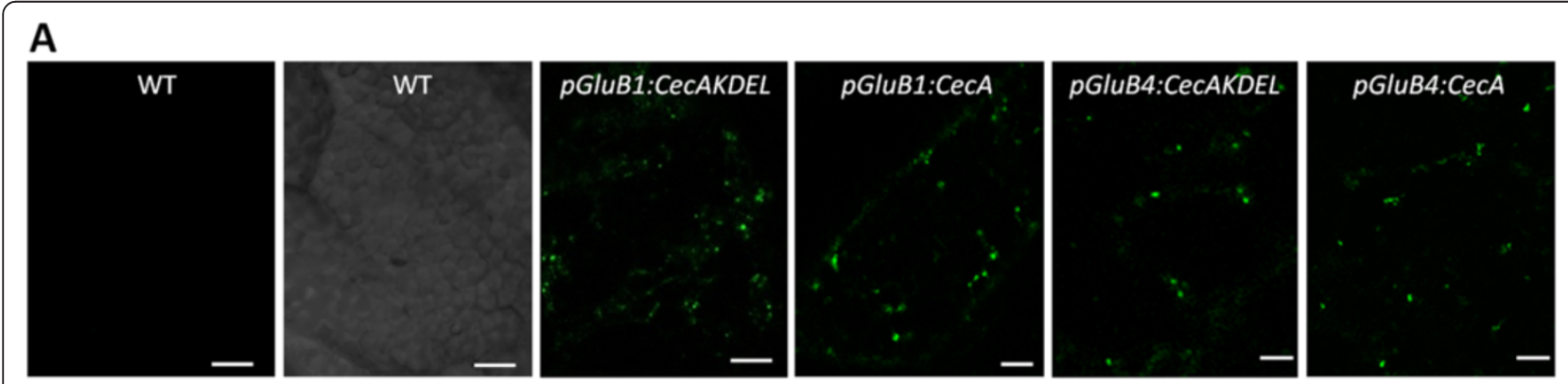

\section{B}
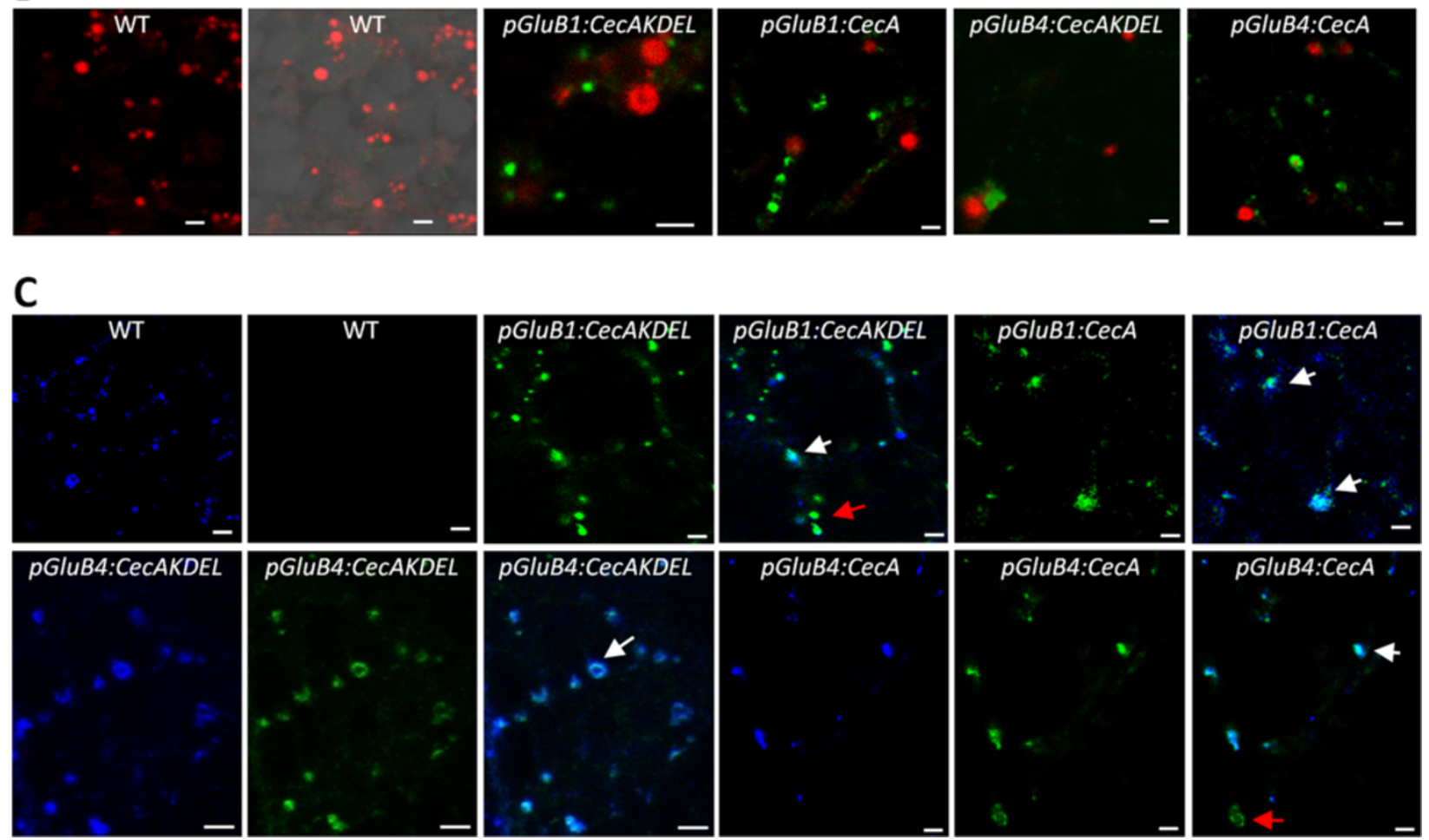

Figure 4 Cecropin A accumulates in type II protein bodies. Confocal fluorescent images of peripheral endosperm cells from wild-type (WT) or transgenic seeds carrying the transgenes indicated. Cecropin A was immunodetected and visualized in green using an AlexaFluor488-conjugated secondary antibody. Prolamine-containing PBs (PB-I marker) were stained with rhodamine B hexyl ester and visualized in red. Glutelin-containing PBs (PB-II marker) were immunodetected using AlexaFluor647-conjugated anti-glutelin antibodies and visualized in blue. Sections were single fluorescent labelled for cecropin A (A) or double fluorescent labelled for cecropin A and prolamines (B) or for cecropin A and glutelins (C). Images correspond to sequential scan single slides. Merged images are shown in B and C. Scale bars correspond to $10 \mu \mathrm{m}$ (A) or $2 \mu \mathrm{m}$ (B and C). Red arrows indicate single immunolabelled vesicles and white arrows double immunolabelled vesicles. 
cecropin A, were packed into PB-II together with glutelin storage proteins in the endosperm cells of transgenic rice seeds. Therefore, the same subcellular localization of cecropin A in PB-II is observed when either the GluB1 or the GluB4 signal peptides is added at the $\mathrm{N}$-terminal, and independently of the KDEL signal at the C-terminal.

\section{Identification of in planta-produced cecropin A by MS analysis}

To verify that in planta-produced cecropin A was correctly synthesized, subcellular fractions enriched in PBs were analysed by mass spectrometry (MS). To do this, protein fractions were separated by SDS-PAGE. The gel pieces in the molecular weight range for immunoreactive cecropin A were then cut, digested with trypsin, and MS analysed. The peptide AGPAVAVVGQATQIAK (monoisotopic mass $1479.84 \mathrm{Da}$ ), corresponding to the $\mathrm{C}$ terminal region of the cecropin A sequence (Figure 5), was unequivocally identified in all the transgenic samples and was not detected in wild-type samples. This peptide was identified in the gel slices in which monomeric and dimeric cecropin A forms were immunodetected (4 and $8 \mathrm{kDa}$, respectively). The expected tryptic peptides FSIYFCVLLLCHGSMAK and LSIYFCVLLLCHGSMAK for the GluB1 or GluB4 signal peptide-cecropin A combinations were not detected by MS analysis in any of the transgenic samples, this suggests that the peptide was correctly processed in each case. These MS data confirmed the presence of cecropin A in the transgenic rice seeds.

\section{Resistance of cecropin A rice seeds to seed-borne pathogens}

To test the functionality of the cecropin A produced in the rice seeds, transgenic seeds were evaluated for resistance to rice seed pathogens; both fungal and bacterial. Initially, cecropin A-seeds were inoculated with spores of Fusarium verticillioides, a fungal pathogen of rice seeds. Cecropin A-seeds were able to germinate and survive in the presence of this fungal pathogen. However, under the same experimental conditions, both wild-type and empty

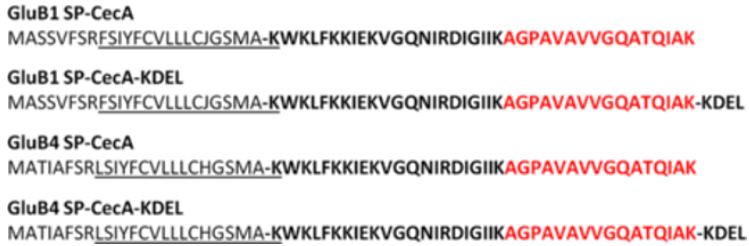

Figure 5 Amino acid sequence of chimeric cecropin A peptides. Plain text sequences correspond to the signal peptide sequence of glutelin B1 (GluB1 SP) or glutelin B4 (GluB4 SP) storage proteins; bold sequences to the mature cecropin A peptides; red sequences to the tryptic peptide identified by MS analysis, and underlined sequences to tryptic peptides undetected by MS analysis. vector transformed seeds failed to germinate (Figure 6). The quantification of the germination rate after fungal infection revealed a higher germination capacity of cecropin A-seeds than that of wild-type or empty vector seeds (Figure 6). Some differences in the resistance to infection by $F$. verticillioides between the lines were observed. Disease resistance correlated with cecropin A accumulation, the seeds accumulating lower cecropin A levels exhibited lower germination capacity in the presence of the fungal pathogen. For instance, line $p$ GluB1:CecA\#3 showed low cecropin A accumulation (Figure 1B) and low germination rates after inoculation with $F$. verticillioides (Figure 6).

Finally, cecropin A-accumulating seeds were assayed for resistance against Dickeya dadantii, a bacterial pathogen of rice. Germination of wild-type and empty vector seeds in bacterial suspensions was severely affected, whereas cecropin A-accumulating seeds were able to germinate and grow under the same experimental conditions (Figure 7A). The quantification of the cecropin A-seed germination rates after seven days in contact with the bacterial pathogen and in comparison with wild-type seeds, showed a clear improvement in seed germination (Figure 7B). All the seeds assayed, transgenic and wild-type, showed the same germinative capacity in the absence of bacterial infection (data not shown). These results demonstrate that cecropin A accumulation in rice seeds confers protection against seed fungal and bacterial pathogens, suggesting that the in planta-produced cecropin A is biologically active.

\section{Discussion}

In the present study, we generated transgenic rice plants that produce bioactive cecropin A in their seed endosperm. Stable integration and inheritance of transgenes was demonstrated. Our transgenic rice seeds tolerated the accumulation of this bioactive peptide without any major change in germination rate or seed viability; thus indicating that rice seeds can sustain the production of this AMP. Therefore, our work demonstrates the usefulness of the GluB1 and GluB4 promoters to drive strong and tissue-specific expression of $C e c A$ genes in rice seeds. High activity in the rice endosperm was reported for these two promoters, with GluB4 activity being slightly higher than that of GluB1 [31]. Consistently with those findings, we detected specific accumulation of cecropin A on seed endosperms, and not in vegetative tissues, when $\mathrm{Cec} A$ gene expression was driven by either of these two promoters. While, similar accumulation levels were observed with the two promoters assayed, the accumulation levels were higher than those of seeds of transgenic plants that constitutively express the $\operatorname{Cec} A$ gene controlled by the strong maize ubiquitin-1 promoter. Moreover, the endosperm-specific expression of $\operatorname{Cec} A$ genes had no negative effects on the normal growth and development of the rice plant; whereas important effects on plant fitness have been 


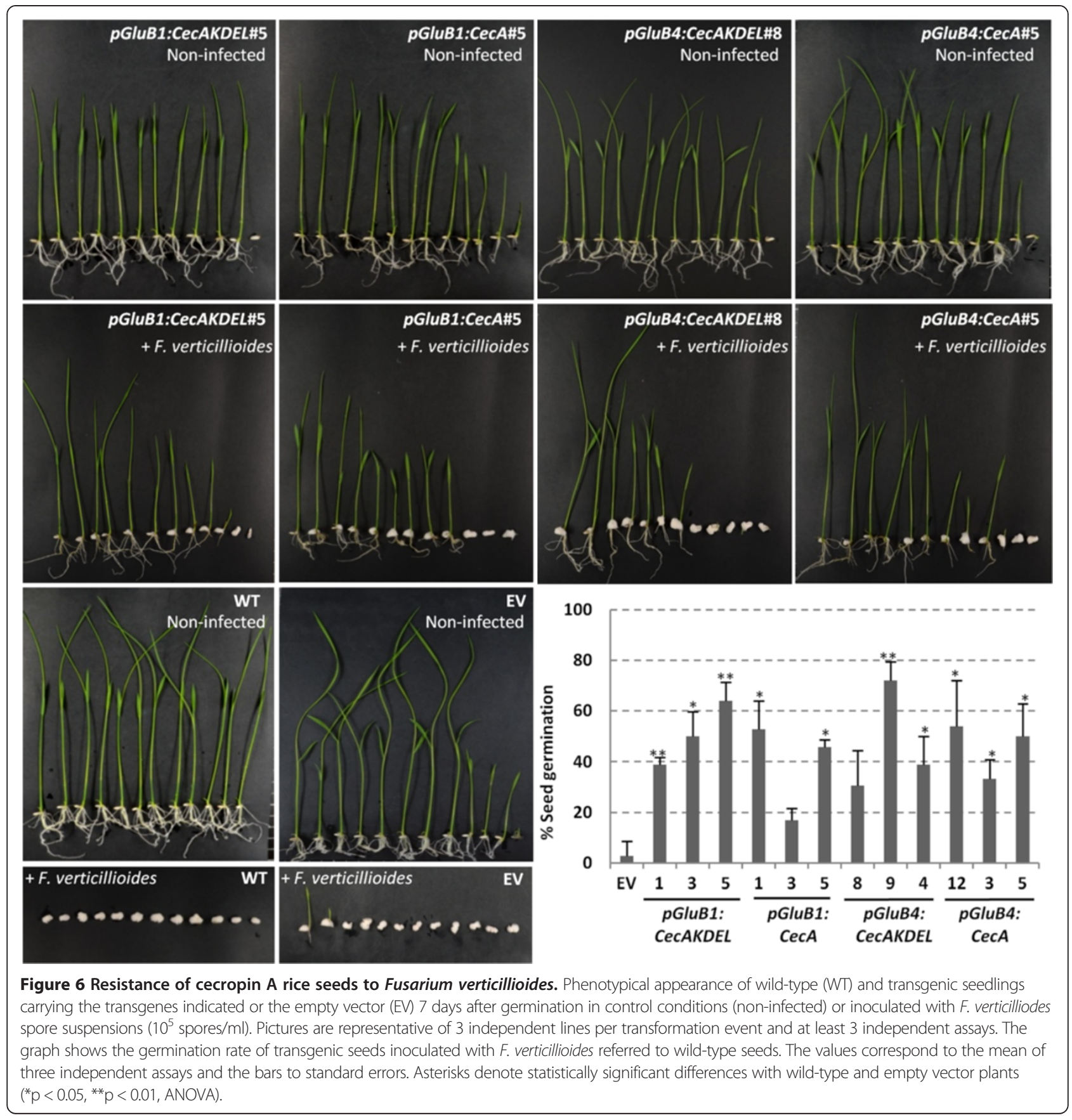

reported in transgenic rice plants that constitutively express transgenes encoding cecropin A or cecropin A-derived AMPs [30,35]. As an additional benefit, the seed-specific accumulation of the cecropin A limits the exposure of the beneficial microbes in the rhizosphere to AMPs.

Concerning the study of targeting mechanisms, in this work we analysed the effects of the N-terminal signal peptide of a rice glutelin, either GluB1 or GluB4, and of the presence or absence of C-terminal KDEL tag. These signal peptides are known to guide translocation of the GluB1 and GluB4 storage proteins into the ER lumen and to be essential for transfer to $\mathrm{PBs}$ [25]. Immunofluorescence and microscopic visualization of the transgenic seed tissues revealed that cecropin A accumulated in the glutelincontaining storage vacuole of endosperm cells, when either signal peptide was fused to the cecropin A. This subcellular localization was observed in all transgenic seeds, including those that accumulated the cecropin A tagged with the KDEL signal. Thus, it appears that the GluB1 or GluB4 N-terminal signal peptide includes the sorting signals necessary to direct this peptide to the PB-II 


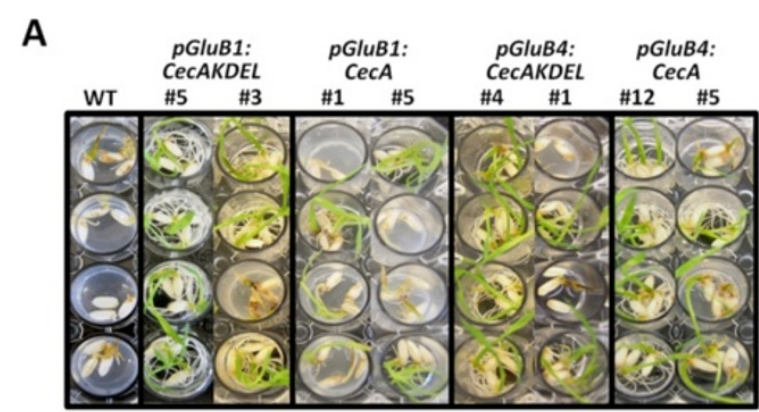

B

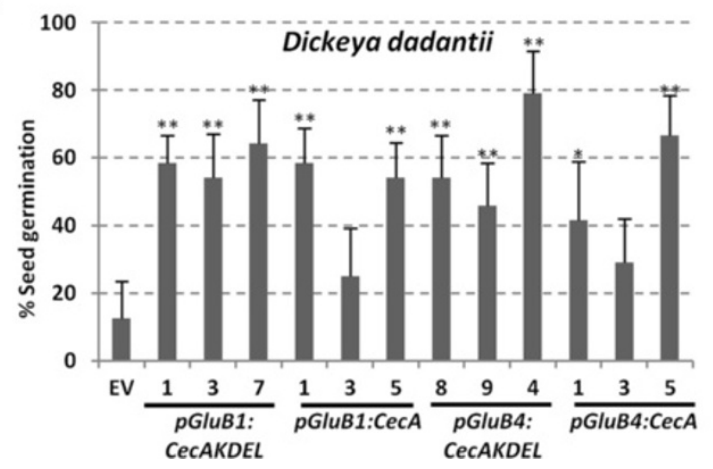

Figure 7 Resistance of cecropin A rice seeds to Dickeya

dadantii. A. Phenotypical appearance of wild-type (WT) or transgenic seedlings carrying the transgenes indicated after 7 days of germination in contact with $D$. dadantii bacterial suspensions $\left(10^{4} \mathrm{CFU} / \mathrm{ml}\right)$. Pictures are representative of at least 2 independent assays. B. Germination rate of transgenic seeds inoculated with $D$. dadantii referred to wild-type seeds. The values correspond to the mean of two independent assays and the bars to standard errors. Asterisks denote statistically significant differences with wild-type and empty vector plants $\left({ }^{*} p<0.05\right.$, ${ }^{* *} p<0.01$, ANOVA).

and overpowers the KDEL ER retention signal. Unexpected accumulation of KDEL-tagged recombinant seed proteins has previously been reported and is not fully understood [36-39]. Most KDEL-tagged recombinant seed proteins have been reported to accumulate primarily, or exclusively in ER-derived PBs or PB-I [39]. Presumably, protein sorting to PBs might not only rely on the presence of specific targeting signals in the polypeptide but also might depend on the intrinsic properties of the protein or possible interactions with other proteins in the ER lumen $[24,39]$. For instance, protein aggregation has been reported as a determinant of sorting to PBs $[24,40]$. There is then the possibility that the specific physico-chemical properties of the cecropin A may be responsible for its localization in the PB-II. In favour of this hypothesis, the cecropin A peptide has amphipathic properties with a structure where hydrophobic residues are clustered into a separated domain, which may confer a tendency for self-aggregation, as proved by its dimeric form in the rice protein extracts. Moreover, cecropin A is a strongly cationic peptide and this may facilitate its interaction with the acidic glutelins during their transport to PSVs, and then they may sort together to the same organelle. However, some cecropin A-containing bodies from which the glutelin proteins were excluded were also visualized, indicating that cecropin A could also accumulate in other ER-derived PBs. Further studies are needed to clarify the molecular determinants of cecropin A accumulation into the PB-II in seeds. Be that as it may, the important result is the compartmentalization of the cecropin A antimicrobial peptide inside subcellular organelles, which protect the peptide from endogenous proteases, thereby offering stability and allowing it to accumulate in rice tissues. Cecropin peptides are known to be highly susceptible to plant proteases and therefore their accumulation in plant tissues is not straightforward [32]. In addition, sequestration of this AMP into a storage organelle, such as PBs, would reduce its toxicity to the host plant and cecropin A seeds were indeed viable and showed a normal germination rate.

Transgenic plants expressing the cecropin $A$ gene under the control of either promoter with the KDEL extension, or not, were evaluated in terms of cecropin A accumulation in seeds. Accumulation ranged from 10 to $100 \mathrm{ng}$ per seed, as measured via immunoblot analysis. There were differences in cecropin A accumulation, which were mainly associated with variability of transgene expression between independently generated lines for each transformation event. Even the attachment of the KDEL signal to cecropin A appears not to have an important effect on its accumulation in rice seeds (i.e., the $p$ GluB1:CecAKDEL and $p$ GluB1:CecA, or pGluB4: CecAKDEL and $p$ GluB4:CecA lines accumulated similar levels of cecropin A. This is despite the fact that several reports indicate that the presence of the KDEL signal sequence enhances the stability and yield of some recombinant proteins in seeds $[14,41]$. Rice endosperm has been used to produce several valuable recombinant proteins, including antibodies, vaccines and other pharmaceuticals [13-15,39,41-43]. For several of these proteins, the reported accumulation was higher than the cecropin A levels in our transgenic seeds; ranging from $1 \mu \mathrm{g} / \mathrm{seed}$ for the human interleukin-10 protein [44], to the $60 \mu \mathrm{g} / \mathrm{seed}$ for the chimeric tolerogen $7 \mathrm{Crp}$ protein [41], and up to $200 \mu \mathrm{g} / \mathrm{seed}$ for chimeric tolerogen TPC7 [39]. However, difficulties in accumulating small peptides (of fewer than 50 residues) in rice endosperm have also been reported and associated with transgene silencing and instability of transgene products in plant cells [45-48]. Thus small peptides have generally been produced through tandem repeats or fusion to carrier proteins $[41,45-49]$, requiring downstream processing to deliver the peptide of interest. Taking into account the peptide size, the amount of the small cecropin A peptide (37 amino acids, $4 \mathrm{kDa}$ ) accumulated in rice seeds ranged from 2.5 to $25 \mathrm{pmols} / \mathrm{seed}$. These values are 
within the average to the reported accumulation of peptides when considering only the size of the peptide with the total fusion protein, such as 1.18 or 51.47 pmols/ seed of the chimeric tolerogen $3 \mathrm{Crp}[47,48]$ or 6.25 pmols/seed of the tolerogen Cryj I and Cryj II [50]. Additionally, underestimation of cecropin A accumulation based on immunoblot detection cannot be ruled out, since difficulties in Western blot analysis and immunodetection of other basic short peptides have been reported [51]. Nevertheless, the usefulness of producing single cecropin A peptides is not only determined by the level of accumulation in transgenic rice seeds, but also by the potency of cecropin A as an antimicrobial agent for the target pathogens without additional processing. In this sense, previous studies on the antimicrobial activity of cecropin A and cecropin A-derived peptides have shown their effectiveness at very low micromolar concentrations in terms of growth inhibition of economically important phytopathogens, including the fungi F. solani, F. verticillioides and Phytophthora infenstans, and the bacteria Erwinia amylovora, Pseudomonas syringae and Xanthomonas axonapodis [27,28,52,53].

The targeting of endosperm PBs not only conferred stability and reduced the toxicity of cecropin A, thereby allowing its accumulation in plant cells, but it also facilitated its purification from rice seeds. PBs are dense organelles that can easily be isolated by centrifugation $[26,54]$. This is particularly relevant here, since downstream processing of plant material to purify products greatly increases the production costs of recombinant proteins when using plants as biofactories [10]. A simple procedure based on two-step centrifugation was implemented here to obtain enriched cecropin A-containing PB fractions. Further studies are required to set up and optimize largescale purification of cecropin A from seeds for potential applications in crop protection or food preservation. The production system for cecropin A described here using rice endosperm as biofactories can potentially be extended to other AMPs, although this needs to be evaluated for AMPs of different sizes, structures or mechanisms of action.

Finally, the observations that the in planta-produced cecropin A is biologically active and that accumulation of cecropin $\mathrm{A}$ in rice seeds confers protection against fungal and bacterial pathogens have additional implications for plant protection. In the present work, disease resistance against two important rice pathogens was evaluated. The fungus $F$. verticillioides has been associated with the bakanae disease in rice [55], which occurs widely throughout Asia and sporadically in other rice producing areas, and causes important crop losses worldwide. Moreover, F. verticillioides is a seed-borne and seed-transmitted pathogen that not only causes yield losses but also decreases the quality of grain by producing hazardous mycotoxins [56].
The cecropin A-seeds also showed enhanced resistance against $D$. dadantii, previously known as Erwinia chrysanthemi, the causal agent of foot rot of rice [57,58]. Resistance to $F$. verticillioides and $D$. dadantii in transgenic seeds indicates that cecropin A accumulation could be a useful strategy for engineering broad-spectrum protection in rice grain.

\section{Conclusions}

Rice seeds can sustain the production of biologically active cecropin A, and presumably other antimicrobial peptides with similar properties. Confining the accumulation of AMP within subcellular compartments, specifically protein bodies, and limiting its production to the rice endosperm avoids the potential negative impact of its production in seed viability and seedling growth. This work has implications for molecular farming since it demonstrates the potential of rice seeds as biofactories for antimicrobial peptides and also for plant protection by showing that production of the antimicrobial peptide cecropin A is a useful strategy for engineering broadspectrum protection against pathogen infection in rice grains.

\section{Methods}

\section{Isolation of rice glutelin gene promoters}

The promoters and the signal peptide sequence of the two rice glutelin genes, GluB1 and GluB4, were amplified by PCR from rice (Oryza sativa cv. Senia) genomic DNA using Taq DNA polymerase (Invitrogen). The primer pairs used for the amplification of each promoter are indicated in Additional file 3. The amplified fragments were inserted into the pGEMT-easy vector (Promega) and their nucleotide sequences determined.

\section{Construction of plant expression vectors}

Four vectors containing a codon-optimized synthetic $\operatorname{Cec} A$ gene were prepared for plant transformation. The scheme of the constructs is presented in Figure 1A. Two of them were designed for the production of cecropin A and the other two for C-terminal KDEL-tagged cecropin A. $C e c A$ gene expression was under the control of the endosperm-specific promoters of either the GluB1 or the GluB4 genes including the signal peptide sequence for the corresponding glutelin protein, and the terminator signal of the nopaline synthase gene. For vector preparation, the nos terminator was inserted as a BamHI-SacI fragment downstream of the promoter fragments in the pGEMTeasy vector; these restriction sites were incorporated into the oligonucleotides used for the PCR amplification of the nos terminator. Next, the synthetic cecA genes were inserted as $B a m H I$ fragments between the promoter and the nos terminator. The corresponding fragments were obtained by PCR amplification using the oligonucleotides 
that incorporated the $\mathrm{BamHI}$ restriction sites (Additional file 3 ) from the previously described synthetic $\mathrm{Cec} A$ genes [30]. Finally, the complete cassettes for the expression of the $C e c A$ gene under the control of the glutelin promoters as $K p n \mathrm{I}-\mathrm{SacI}$ fragments, and for the expression of the $C e c A-K D E L$ gene as $K p n I$ fragments, were cloned into the pCAMBIA 1300 vector. This resulted in the plasmids presented in Figure 1A. All the constructs used for rice transformation were verified by nucleotide sequencing.

\section{Production of transgenic rice plants}

Transgenic rice lines (O. sativa cv. Senia or cv. Ariete) were produced by Agrobacterium-mediated transformation of embryonic callus derived from mature embryos, as described previously [59]. The expression vector constructs were transferred to Agrobacterium tumefaciens EHA105 [60]. The parent pCAMBIA 1300 vector already contains the hygromycin phosphotransferase gene (hptII) in the T-DNA region, affording hygromycin resistance. Transgene insertion was confirmed in the regenerated plants by PCR analysis using leaf genomic DNA as the template. The positive transformants were grown under containment greenhouse conditions to obtain homozygous transgenic lines in the T2 generation. Homozygous lines were identified by segregation of hygromycin resistance. The transgene copy number was estimated using quantitative PCR in the T2 homozygous lines by comparison with standard curves for the $\operatorname{Cec} A$ gene at different DNA concentrations (Additional file 2), using a previously described method [35,61]. Rice plants transformed with the empty vector (pCAMBIA 1300) were also produced for this study; rice plants constitutively expressing the CecA gene were also assayed [30]. All rice plants were grown at $28^{\circ} \mathrm{C} \pm 2{ }^{\circ} \mathrm{C}$ under a $14 \mathrm{~h} / 10 \mathrm{~h}$ light/dark photoperiod.

\section{In situ immunodetection of cecropin A in whole seeds}

Cecropin A accumulation in the transgenic rice seeds was analysed by in situ immunodetection using antibodies against cecropin A [30], according to the method of $\mathrm{Qu}$ and collaborators [62] with minor modifications. These included a stronger and extended blocking procedure (overnight incubation of sections in $10 \%$ skimmed milk in TBST), reaction with cecropin A antiserum (2 hours incubation with a 1:500 dilution), and the colorimetric detection of the antigen-antibody complexes using the NBT/BCIP substrate of alkaline phosphatase (Roche).

\section{Immunolocalization of cecropin A in PBs}

Dehulled mature seeds were used for immunofluorescent detection of cecropin $\mathrm{A}$ in rice $\mathrm{PBs}$ using $10 \%$ skimmed milk as a blocking reagent [63]. Immunoreaction with rabbit anti-cecropin A antibodies (1:200 dilution) were visualized using the fluorescent labelled AlexaFluor488 anti-rabbit IgG as secondary antibodies (Molecular Probes, 1:5000 dilution). Anti-glutelin antibodies (kindly provided by Dr. Okita, Washington State University, USA) were conjugated to the fluorophore AlexaFluor647 using the APEX antibody labelling kit (Molecular Probes) and were used for fluorescent immunodetection of PB-II. PB-I were fluorescently labelled with rhodamine B hexyl ester (Molecular Probes). Fluorescent endosperm cells were analysed with a confocal laser scanning microscope (Leica TCS-SP5II). The AlexaFluor488 fluorophore was excited with a blue argon ion laser $(488 \mathrm{~nm})$ and the emitted light was collected between 500 and $550 \mathrm{~nm}$. The rhodamine was excited with a HeNe laser (543 nm) and the emitted light was collected between 570 and $650 \mathrm{~nm}$; and the AlexaFluor647 fluorophore was excited with a $\mathrm{HeNe}$ laser $(633 \mathrm{~nm})$ and the emitted light was collected between 650 and $750 \mathrm{~nm}$. The resulting images were processed using Leica LAS-AF software (version 1.8.2).

\section{Subcellular fractionation}

Ten dehulled mature seeds per line were water imbibited for one hour, and then ground in a mortar at $0^{\circ} \mathrm{C}$ in $5 \mathrm{ml}$

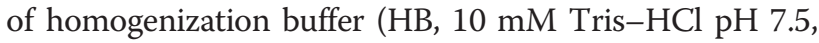
$\mathrm{KCl} 50 \mathrm{mM}, \mathrm{MgCl} 210 \mathrm{mM}$, EDTA $10 \mathrm{mM}$ and plant protease inhibitors) containing $10 \%$ sucrose. The homogenates were filtered through two layers of Miracloth (Calbiochem) to remove tissue debris and centrifugated at $100 \times \mathrm{g}$ for $5 \mathrm{~min}$ at $4^{\circ} \mathrm{C}$. Aliquots of the supernatants (3 ml) were layered onto discontinuous sucrose density gradients $(20 \%, 30 \%, 50 \%$, and $70 \% \mathrm{w} / \mathrm{v})$ in $\mathrm{HB}$ buffer and centrifugated at $4^{\circ} \mathrm{C}$ for $2 \mathrm{~h}$ at $24000 \times \mathrm{g}$ in a Beckman SW40 Ti rotor. Equivalent aliquots of supernatant, interphase fractions and pellet were analysed by SDS-PAGE followed by protein staining in Coomassie blue or immunoblot using specific antibodies.

\section{Preparation of protein extracts and immunoblot analysis}

Protein extracts were prepared from dehulled mature seeds (10 seeds, $200 \mathrm{mg}$ ), after one hour water imbibition, using a simplified method for enrichment in dense organelles. The same protocol was used for vegetative tissues $(200 \mathrm{mg})$. The plant material was ground and homogenized in a sucrose-containing extraction buffer (10 mM phosphate buffer pH7.5, 0.6 M sucrose). Then the cellular debris and starch were removed from the homogenates by low speed centrifugation (200 x g), and PB enriched fractions were obtained by high speed centrifugation $(2000 \times \mathrm{g})$ and resuspended directly in SDSloading buffer. Protein extracts were separated on tricine-SDS-PAGE (16.5\%), transferred to a nitrocellulose membrane (Protran $0.2 \mu \mathrm{m}$ ) and immunodetected as described previously [30]. To determine cecropin A 
accumulation in seed protein extracts, different amounts of cecropin A (GeneScript) were used as standards. Chemiluminescent reaction was captured with an ImageQuant ${ }^{\mathrm{mm}}$ LAS4000 (GE Healthcare) digital imaging system. Signal intensity was quantified using MultiGauge V3.0 (FujiFilm) software. Quantification was performed in 3 independent experimental replicas using at least 3 independent lines per transgene and 10 seeds per line.

\section{Mass Spectrometry Analysis}

Subcellular fraction samples containing PBs were diluted in 5 volumes of ultrapure water and precipitated by centrifugation for $45 \mathrm{~min}$ at $75000 \times \mathrm{g}$. Then, proteins were resuspended in SDS-loading buffer and separated by tricine-SDS-PAGE (16.5\%). Two bands were excised from the gel between the dye front and the $20 \mathrm{kDa}$ marker (Sigma). For in-gel digestion, gel pieces were washed in $25 \mathrm{mM} \mathrm{NH}_{4} \mathrm{HCO}_{3}, \mathrm{pH} 8,50 \%$ acetonitrile, dehydrated with $100 \%$ acetonitrile and digested with $50 \mu \mathrm{l}$ of a trypsin (Promega) solution in $25 \mathrm{mM}$ $\mathrm{NH}_{4} \mathrm{HCO}_{3}, \mathrm{pH} 8$ overnight at $37^{\circ} \mathrm{C}$. Peptides were extracted successively with $2 \% \mathrm{v} / \mathrm{v}$ formic acid and acetonitrile/water $(80 / 20 \mathrm{v} / \mathrm{v})$. Extracts were combined, dried and dissolved in $0.1 \%$ formic acid before LC-MS analysis.

The protein digests were analysed using a QTOF mass spectrometer (Maxis Impact; Bruker Daltonik $\mathrm{GmbH}$ ), interfaced with a nano-HPLC Ultimate 3000 (Dionex). Samples were first loaded onto the precolumn (C18 PepMap100, $300 \mu \mathrm{m} \times 5 \mathrm{~mm}, 5 \mu \mathrm{m}, 100$ A, Dionex) at a flow rate of $20 \mu \mathrm{l} / \mathrm{min}$ for 5 minutes with solvent A $(0.1 \%$ formic acid, $2 \%$ acetonitrile in water, $\mathrm{v} / \mathrm{v} / \mathrm{v})$. After pre-concentration, peptides were separated in the reversed-phase column (C18 PepMap100, $75 \mu \mathrm{m} \times 250 \mathrm{~mm}, 3 \mu \mathrm{m}, 100$ A, Dionex) at a flow rate of $0.3 \mu \mathrm{l} / \mathrm{min}$ using a two-step linear gradient from $7 \%$ to $25 \%$ solvent B $(0.1 \%$ formic acid, $90 \%$ acetonitrile in water, $\mathrm{v} / \mathrm{v} / \mathrm{v}$ ) from 0 to $70 \mathrm{~min}$ and from $25 \%$ to $40 \%$ solvent $\mathrm{B}$, from 70 to $90 \mathrm{~min}$, and eluted into the mass spectrometer. The instrument was operated in the positive ion mode and the captive-spray source parameters were: a capillary voltage of $1300 \mathrm{~V}$, a dry gas flow rate of $41 / \mathrm{min}$ at $150^{\circ} \mathrm{C}$. After an initial MS scan at $5 \mathrm{~Hz}$ over the mass range of $50-2200 \mathrm{Th}$, the 30 most intense precursors were fragmented by collisioninduced dissociation. The MS/MS raw data were analysed using Data Analysis software (Bruker Daltonik $\mathrm{GmbH}$ ) to generate the peak lists. A local database including the cecropin A sequence was queried using the Mascot search engine (v. 2.2.04; Matrix Science) with the following parameters: trypsin as enzyme, 1 missed cleavage allowed, oxidation of methionine as variable modification, $15 \mathrm{ppm}$ in MS and 0.05 Da in MS/MS.

\section{Disease resistance assays}

Resistance to $F$. verticillioides was assayed in transgenic rice seeds by inoculation with spore suspensions at different concentrations $\left(10^{3}\right.$ or $10^{5}$ spores $\left./ \mathrm{ml}\right)$ on MS medium without sucrose as previously described [64]. Inhibition of germination was determined by comparison to the seeds inoculated with sterile water 7 days post imbibition. The $F$. verticillioides isolate used in this work was collected from rice plants in Spain and provided by the Plant Protection Facilities of the Generalitat de Catalunya.

Resistance of cecropin A-seeds to D. dadantii (formely known as Erwinia chrysanthemi isolate AC4150) was evaluated by implementing a high-throughput assay derived from a previously described assay [64]. The seeds were germinated in 24-well plates (3 seeds per well) in $1 \mathrm{ml}$ of sterile water or bacterial culture suspensions $\left(10^{4} \mathrm{CFU}\right)$ for 7 days. Inhibition of germination was evaluated as the ratio to non-inoculated seeds and by comparison to wild-type untransformed seeds.

\section{Additional files}

Additional file 1: Confirmation of the transgene insertion in the genome of transgenic rice plants. PCR analysis on genomic DNA purified from leaves of wild-type (wt) or transgenic lines carrying the indicated transgenes. Plasmidic DNA was used as a positive control (+). Arrows indicate the position of the specific oligonucleotides used for PCR amplification. The size of amplified fragments showed full length transgene insertion.

Additional file 2: Estimated transgene copy number in the transgenic lines by qPCR analysis.

Additional file 3: List of primers used in the study. Underlined are the restriction sites used for cloning purposes.

\section{Competing interest}

The authors declare no competing interests.

\section{Authors' contribution}

MB carried out the rice transformation experiments, molecular characterization and phenotype analysis of the transgenic lines, including the fungal infection assays. LM prepared all the constructs for rice transformation and contributed to the rice transformation as well as the molecular and phenotype analysis of transgenic lines, including the bacterial infection assays. El and MR carried out the MS analysis. SC participated in the design of the study and helped to write the manuscript. DM and EG contributed to the rice transformation experiments. EB participated in the bacterial infection assays. EM, BSS and MC conceived, designed and coordinated the study. MC wrote the manuscript. All the authors read and approved the final manuscript.

\section{Acknowledgements}

We thank Dr. Okita of Washington State University for kindly providing us with rice glutelin antibodies. We are grateful to G. Peñas for collaborating with parts of this work, to P. Fontanet for help with greenhouse plants and to M. Amenós for help with confocal microscopy. We also acknowledge the REFUGE platform (http://www.refuge-platform.org/) funded by Agropolis Fondation for assistance in rice transformation. This work was supported by SEPSAPE grants (Plant-KBBE programme) EUI2008-03769 and EUI2008-03572 from the Spanish Ministry of Science and Innovation, and ANR-08-KBBE-010 from the French Research Agency. We also thank the Consolider-Ingenio 
CSD2007-00036 award to CRAG and the Department d'Innovació, Universitats I Empresa of the Generalitat de Catalunya (Xarxa de Referencia en Biotecnología, Xarxa de Referència en Tecnologia dels Aliments, SGR09626, and 2008SGR812) for support. We acknowledge support of the publication fee by the CSIC Open Access Publication Support Initiative through its Unit of Information Resources for Research (URICl).

\section{Author details}

${ }^{1}$ Centre for Research in Agricultural Genomics (CRAG), CSIC-IRTA-UAB-UB. Edifici CRAG, Campus de la UAB, 08193 Bellaterra, Barcelona, Spain. ${ }^{2}$ Institute of Food and Agricultural Technology-CIDSAV-XaRTA, University of Girona, Girona 17071, Spain. ${ }^{3}$ Mass Spectrometry Proteomics Platform-MSPP, Laboratoire de Protéomique Fonctionnelle, INRA, Cedex 1, Montpellier 34060, France. ${ }^{4}$ CIRAD, Centre de Coopération Internationale en Recherche Agronomique pour le Développement, UMR AGAP, Genetic Improvement and Adaptation of Mediterranean and Tropical Plants, Cedex 5, Montpellier 34398, France.

Received: 4 October 2013 Accepted: 14 April 2014

Published: 22 April 2014

\section{References}

1. Zasloff M: Antimicrobial peptides of multicellular organisms. Nature 2002, 415:389-395.

2. Montesinos E: Antimicrobial peptides and plant disease control. FEMS Microbiol Lett 2007, 270:1-11.

3. Lopez-Garcia B, Segundo B, Coca M: Antimicrobial peptides as a promising alternative for plant disease protection. In Small wonders: peptides for disease control. Edited by Rajasekaran K, Cary JW, Jaynes J, Montesinos E. Washintong DC: ACS Books; 2012:263-294.

4. Marcos JF, Muñoz A, Perez-Paya E, Misra S, Lopez-Garcia B: Identification and rational design of novel antimicrobial peptides for plant protection. Annu Rev Phytopathol 2008, 46:273-301.

5. Keymanesh K, Soltani S, Sardari S: Application of antimicrobial peptides in agriculture and food industry. World J Microbiol Biotechnol 2009, 25:933-944

6. Rydlo T, Miltz J, Mor A: Eukaryotic antimicrobial peptides: Promises and premises in food safety. J Food Sci 2006, 71:R125-R135.

7. Hancock RE, Sahl HG: Antimicrobial and host-defense peptides as new anti-infective therapeutic strategies. Nat Biotechnol 2006, 24:1551-1557.

8. da Rocha Pitta MG, da Rocha Pitta MG, Galdino SL: Development of novel therapeutic drugs in humans from plant antimicrobial peptides. Curr Protein Pept Sci 2010, 11:236-247.

9. Peters BM, Shirtliff ME, Jabra-Rizk MA: Antimicrobial peptides: primeval molecules or future drugs? PLOS Pathog 2010, 6(10):e1001067.

10. Twyman RM, Stoger E, Schillberg S, Christou P, Fischer R: Molecular farming in plants: host systems and expression technology. Trends Biotechnol 2003, 21:570-578.

11. Faye $L$, Gomord V: Success stories in molecular farming-a brief overview. Plant Biotechnol J 2010, 8:525-528.

12. Stoger E, Ma JKC, Fischer R, Christou P: Sowing the seeds of success: pharmaceutical proteins from plants. Curr Opin Biotechnol 2005, 16:167-173.

13. Boothe J, Nykiforuk C, Shen Y, Zaplachinski S, Szarka S, Kuhlman P, Murray E, Morck D, Moloney MM: Seed-based expression systems for plant molecular farming. Plant Biotechnol J 2010, 8:588-606.

14. Takaiwa F, Takagi H, Hirose S, Wakasa Y: Endosperm tissue is good production platform for artificial recombinant proteins in transgenic rice. Plant Biotechnol J 2007, 5:84-92.

15. Hennegan K, Yang DC, Nguyen D, Wu LY, Goding J, Huang JM, Guo FL, Huang N, Watkins S: Improvement of human lysozyme expression in transgenic rice grain by combining wheat (Triticum aestivum) puroindoline $b$ and rice (Oryza sativa) Gt1 promoters and signal peptides. Transgenic Res 2005, 14:583-592.

16. Morandini F, Avesani L, Bortesi L, Van Droogenbroeck B, De Wilde K, Arcalis E, Bazzoni F, Santi L, Brozzetti A, Falorni A, Stoger E, Depicker A, Pezzotti M: Non-food/feed seeds as biofactories for the high-yield production of recombinant pharmaceuticals. Plant Biotechnol J 2011, 9:911-921.

17. Rademacher T, Sack M, Arcalis E, Stadlmann J, Balzer S, Altmann F, Quendler H, Stiegler G, Kunert R, Fischer R, Stoger E: Recombinant antibody 2 G12 produced in maize endosperm efficiently neutralizes HIV-1 and contains predominantly single-GlcNAc N-glycans. Plant Biotechnol J 2008, 6:189-201.
18. Li XX, Okita TW: Accumulation of prolamines and glutelins during rice seed development - a quantitative-evaluation. Plant Cell Physiol 1993, 34:385-390

19. Kawakatsu T, Yamamoto M, Hirose S, Yano M, Takaiwa F: Characterization of a new rice glutelin gene GluD-1 expressed in the starchy endosperm. J Exp Bot 2008, 59:4233-4245.

20. Cagampang GB, Perdon AA, Juliano BO: Changes in salt-soluble proteins of rice during grain development. Phytochemistry 1976, 15:1425-1429.

21. Bechtel $D B$, Juliano BO: Formation of protein bodies in the starchy endosperm of rice (Oryza-Sativa-L) - a reinvestigation. Ann Bot 1980, 45:503-509.

22. Nagamine A, Matsusaka H, Ushijima T, Kawagoe Y, Ogawa M, Okita TW, Kumamaru T: A role for the cysteine-rich $10 \mathrm{kDa}$ prolamin in protein body I formation in rice. Plant Cell Physiol 2011, 52:1003-1016.

23. Kumamaru T, Uemura Y, Inoue Y, Takemoto Y, Siddiqui SU, Ogawa M, Hara-Nishimura I, Satoh H: Vacuolar processing enzyme plays an essential role in the crystalline structure of glutelin in rice seed. Plant Cell Physiol 2010, 51:38-46.

24. $|\mathrm{b}| \mathrm{V}$, Stoger $\mathrm{E}$ : The formation, function and fate of protein storage compartments in seeds. Protoplasma 2012, 249:379-392

25. Muntz K: Deposition of storage proteins. Plant Mol Biol 1998, 38:77-99.

26. Khan I, Twyman RM, Arcalis E, Stoger E: Using storage organelles for the accumulation and encapsulation of recombinant proteins. Biotechnol J 2012, 7:1099-1108.

27. Cavallarin L, Andreu D, Segundo BS: Cecropin A-derived peptides are potent inhibitors of fungal plant pathogens. Mol Plant Microbe Interact 1998, 11:218-227.

28. Ferre R, Badosa E, Feliu L, Planas M, Montesinos E, Bardaji E: Inhibition of plant-pathogenic bacteria by short synthetic cecropin a-melittin hybrid peptides. Appl Environ Microbiol 2006, 72:3302-3308.

29. Steiner $H$, Hultmark D, Engstrom A, Bennich H, Boman HG: Sequence and specificity of 2 anti-bacterial proteins involved in insect immunity. Nature 1981, 292:246-248.

30. Coca M, Penas G, Gomez J, Campo S, Bortolotti C, Messeguer J, San Segundo $B$ : Enhanced resistance to the rice blast fungus Magnaporthe grisea conferred by expression of a cecropin A gene in transgenic rice. Planta 2006, 223:392-406.

31. Qu LQ, Takaiwa F: Evaluation of tissue specificity and expression strength of rice seed component gene promoters in transgenic rice. Plant Biotechnol J 2004, 2:113-125.

32. Florack D, Allefs S, Bollen R, Bosch D, Visser B, Stiekema W: Expression of giant silkmoth cecropin-B genes in tobacco. Transgenic Res 1995, 4:132-141.

33. Mills D, Hammerschlag FA, Nordeen RO, Owens LD: Evidence for the breakdown of cecropin-B by proteinases in the intercellular fluid of peach leaves. Plant Sci 1994, 104:17-22.

34. Muench DG, Chuong SDX, Franceschi VR, Okita TW: Developing prolamine protein bodies are associated with the cortical cytoskeleton in rice endosperm cells. Planta 2000, 211:227-238.

35. Nadal A, Montero M, Company N, Badosa E, Messeguer J, Montesinos L, Montesinos E, Pla M: Constitutive expression of transgenes encoding derivatives of the synthetic antimicrobial peptide BP100: impact on rice host plant fitness. BMC Plant Biol 2012, 12:159-180.

36. Arcalis E, Marcel S, Altmann F, Kolarich D, Drakakaki G, Fischer R, Christou P, Stoger E: Unexpected deposition patterns of recombinant proteins in post-endoplasmic reticulum compartments of wheat endosperm. Plant Physiol 2004, 136:3457-3466.

37. Petruccelli S, Otegui MS, Lareu F, Dinh OT, Fitchette AC, Circosta A, Rumbo M, Bardor M, Carcamo R, Gomord V, Beachy RN: A KDEL-tagged monoclonal antibody is efficiently retained in the endoplasmic reticulum in leaves, but is both partially secreted and sorted to protein storage vacuoles in seeds. Plant Biotechnol J 2006, 4:511-527.

38. Torres E, Gonzalez-Melendi P, Stoger E, Shaw P, Twyman RM, Nicholson L, Vaquero C, Fischer R, Christou P, Perrin Y: Native and artificial reticuloplasmins co-accumulate in distinct domains of the endoplasmic reticulum and in post-endoplasmic reticulum compartments. Plant Physio/ 2001, 127:1212-1223.

39. Wang S, Takahashi H, Kajiura H, Kawakatsu T, Fujiyama K, Takaiwa F: Transgenic rice seeds accumulating recombinant hypoallergenic birch pollen allergen bet v 1 generate giant protein bodies. Plant Cell Physiol 2013, 54:917-933. 
40. Takaiwa F, Hirose S, Takagi H, Yang L, Wakasa Y: Deposition of a recombinant peptide in ER-derived protein bodies by retention with cysteine-rich prolamins in transgenic rice seed. Planta 2009, 229:1147-1158.

41. Takagi H, Saito S, Yang LJ, Nagasaka S, Nishizawa N, Takaiwa F: Oral immunotherapy against a pollen allergy using a seed-based peptide vaccine. Plant Biotechnol J 2005, 3:521-533.

42. Nochi T, Takagi H, Yuki Y, Yang L, Masumura T, Mejima M, Nakanishi U, Matsumura A, Uozumi A, Hiroi T, Morita S, Tanaka K, Takaiwa F, Kiyono H: Rice-based mucosal vaccine as a global strategy for cold-chain- and needle-free vaccination. Proc Natl Acad Sci U S A 2007, 104:10986-10991.

43. Nicholson L, Gonzalez-Melendi P, van Dolleweerd C, Tuck H, Perrin Y, Ma JKC, Fischer R, Christou P, Stoger E: A recombinant multimeric immunoglobulin expressed in rice shows assembly-dependent subcellular localization in endosperm cells. Plant Biotechnol J 2005, 3:115-127.

44. Fujiwara Y, Aiki Y, Yang L, Takaiwa F, Kosaka A, Tsuji NM, Shiraki K, Sekikawa K: Extraction and purification of human interleukin-10 from transgenic rice seeds. Protein Expr Purif 2010, 72:125-130.

45. Yasuda H, Tada Y, Hayashi $Y$, Jomori T, Takaiwa F: Expression of the small peptide GLP-1 in transgenic plants. Transgenic Res 2005, 14:677-684.

46. Yasuda $H$, Hayashi $Y$, Jomori $T$, Takaiwa F: The correlation between expression and localization of a foreign gene product in rice endosperm. Plant Cell Physiol 2006, 47:756-763.

47. Takagi H, Hiroi T, Yang L, Takamura K, Ishimitsu R, Kawauchi H, Takaiwa F: Efficient induction of oral tolerance by fusing cholera toxin B subunit with allergen-specific T-cell epitopes accumulated in rice seed. Vaccine 2008, 26:6027-6030.

48. Takagi H, Hiroi T, Hirose S, Yang L, Takaiwa F: Rice seed ER-derived protein body as an efficient delivery vehicle for oral tolerogenic peptides. Peptides 2010, 31:1421-1425.

49. Wakasa $Y$, Zhao H, Hirose S, Yamauchi D, Yamada Y, Yang LJ, Ohinata K, Yoshikawa M, Takaiwa F: Antihypertensive activity of transgenic rice seed containing an 18-repeat novokinin peptide localized in the nucleolus of endosperm cells. Plant Biotechnol J 2011, 9:729-735.

50. Takagi H, Hiroi T, Yang LJ, Tada Y, Yuki Y, Takamura K, Ishimitsu R, Kawauchi $\mathrm{H}$, Kiyono $\mathrm{H}$, Takaiwa F: A rice-based edible vaccine expressing multiple $\mathrm{T}$ cell epitopes induces oral tolerance for inhibition of Th2-mediated IgE responses. Proc Natl Acad Sci U S A 2005, 102:17525-17530.

51. Osusky M, Zhou GQ, Osuska L, Hancock RE, Kay WW, Misra S: Transgenic plants expressing cationic peptide chimeras exhibit broad-spectrum resistance to phytopathogens. Nat Biotechnol 2000, 18:1162-1166.

52. Badosa E, Ferre R, Planas M, Feliu L, Besalu E, Cabrefiga J, Bardaji E, Montesinos E: A library of linear undecapeptides with bactericidal activity against phytopathogenic bacteria. Peptides 2007, 28:2276-2285.

53. Badosa E, Ferre R, Frances J, Bardaji E, Feliu L, Planas M, Montesinos E: Sporicidal activity of synthetic antifungal undecapeptides and control of penicillium rot of apples. Appl Environ Microbiol 2009, 75:5563-5569.

54. Torrent M, Llop-Tous I, Ludevid M: Protein body induction: a new tool to produce and recover recombinant proteins in plants. In Recombinant Proteins from Plants. Edited by Faye L, Gomord V. Heidelberg: Humana Press; 2009:193-208.

55. Wulff EG, Sorensen JL, Lubeck M, Nielsen KF, Thrane U, Torp J: Fusarium spp. associated with rice Bakanae: ecology, genetic diversity, pathogenicity and toxigenicity. Environ Microbiol 2010, 12:649-657.

56. Hinojo MJ, Medina A, Valle-Algarra FM, Gimeno-Adelantado JV, Jimenez M, Mateo R: Fumonisin production in rice cultures of Fusarium verticillioides under different incubation conditions using an optimized analytica method. Food Microbiol 2006, 23:119-127.

57. Mansfield J, Genin S, Magori S, Citovsky V, Sriariyanum M, Ronald P, Dow M, Verdier V, Beer SV, Machado MA, Toth I, Salmond G, Foster GD: Top 10 plant pathogenic bacteria in molecular plant pathology. Mol Plant Pathol 2012, 13:614-629.

58. Goto M: Bacterial foot rot of rice caused by a strain of Erwinia Chrysanthemi. Phytopathology 1979, 69:213-216.

59. Sallaud C, Meynard D, van Boxtel J, Gay C, Bes M, Brizard J, Larmande P, Ortega D, Raynal M, Portefaix M, Ouwerkerk P, Rueb S, Delseny M, Guiderdoni E: Highly efficient production and characterization of T-DNA plants for rice (Oryza sativa L.) functional genomics. Theor Appl Genet 2003, 106:1396-1408.

60. Hood EE, Gelvin SB, Melchers LS, Hoekema A: New Agrobacterium helper plasmids for gene-transfer to plants. Transgenic Res 1993, 2:208-218.
61. Yang LT, Ding JY, Zhang CM, Jia JW, Weng HB, Liu WX, Zhang DB: Estimating the copy number of transgenes in transformed rice by real-time quantitative PCR. Plant Cell Rep 2005, 23:759-763.

62. Qu LQ, Tada Y, Takaiwa F: In situ Western hybridization: a new, highly sensitive technique to detect foreign and endogenous protein distribution in rice seeds. Plant Cell Rep 2003, 22:282-285.

63. Satoh-Cruz M, Crofts AJ, Takemoto-Kuno Y, Sugino A, Washida H, Crofts N, Okita TW, Ogawa M, Satoh H: Protein disulfide isomerase like 1-1 participates in the maturation of Proglutelin within the endoplasmic reticulum in rice endosperm. Plant Cell Physiol 2010, 51:1581-1593.

64. Gomez-Ariza J, Campo S, Rufat M, Estopa M, Messeguer J, San Segundo B, Coca M: Sucrose-mediated priming of plant defense responses and broad-spectrum disease resistance by overexpression of the maize pathogenesis-related PRms protein in rice plants. Mol Plant Microbe Interact 2007, 20:832-842.

doi:10.1186/1471-2229-14-102

Cite this article as: Bundó et al:: Production of cecropin A antimicrobial peptide in rice seed endosperm. BMC Plant Biology 2014 14:102.

\section{Submit your next manuscript to BioMed Central and take full advantage of:}

- Convenient online submission

- Thorough peer review

- No space constraints or color figure charges

- Immediate publication on acceptance

- Inclusion in PubMed, CAS, Scopus and Google Scholar

- Research which is freely available for redistribution

Submit your manuscript at www.biomedcentral.com/submit
C) Biomed Central 